Document downloaded from:

http://hdl.handle.net/10251/63956

This paper must be cited as:

Serna, P.; Corma Canós, A. (2015). Transforming Nano Metal Nonselective Particulates into Chemoselective Catalysts for Hydrogenation of Substituted Nitrobenzenes. ACS Catalysis. 5(12):7114-7121. doi:10.1021/acscatal.5b01846

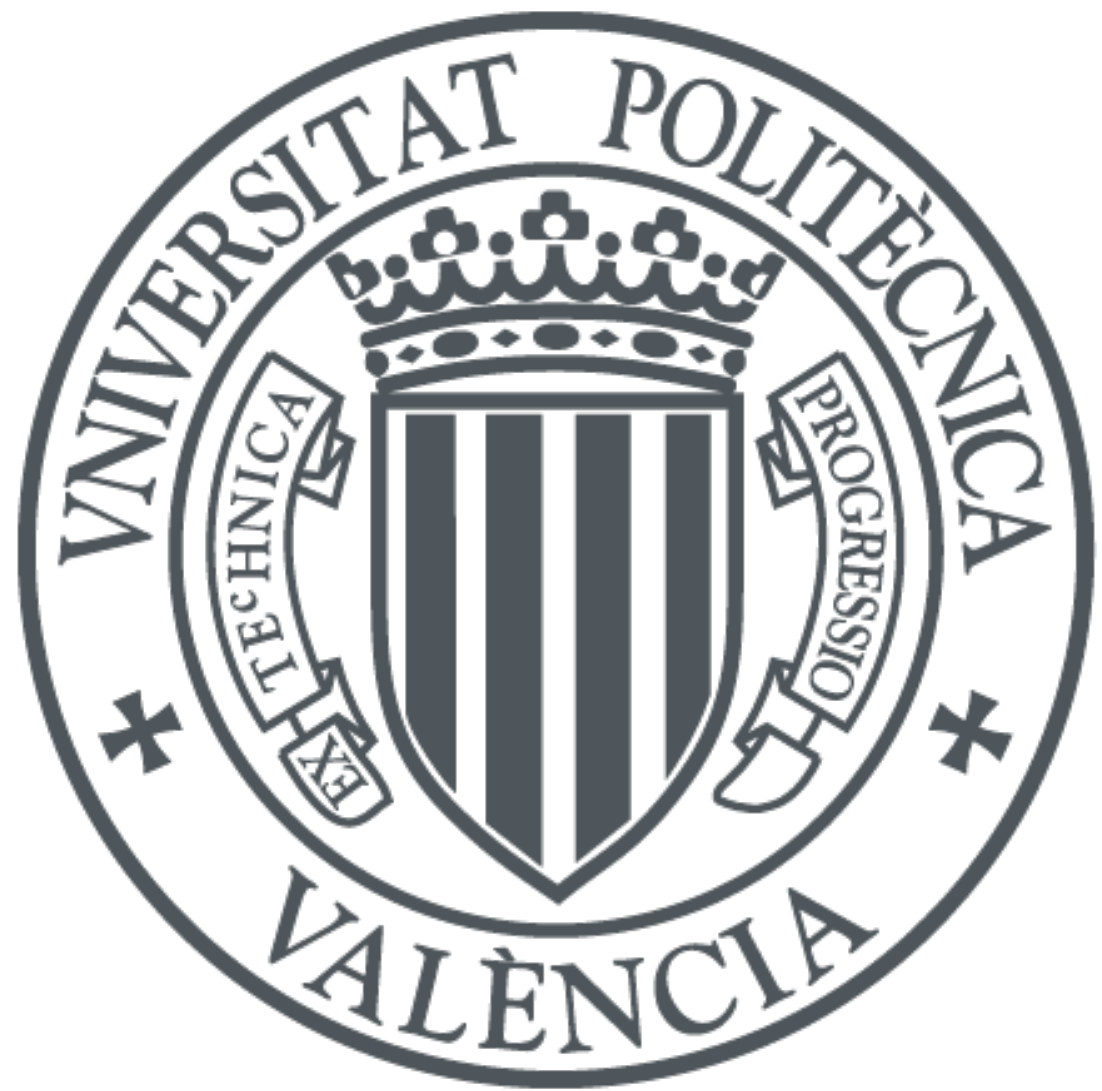

The final publication is available at

http://dx.doi.org/10.1021/acscatal.5b01846

Copyright American Chemical Society

Additional Information 


\title{
Transforming nano metal non selective particulates into chemoselective catalysts for hydrogenation of substituted nitrobenzenes
}

\author{
Pedro Serna, Avelino Corma* \\ Instituto de Tecnología Química. Universidad Politécnica de Valencia-Consejo Superior de Investigaciones \\ Científicas. Avda. de los Naranjos s/n, 46022 Valencia, Spain. Fax: +34 963877800
}

\begin{abstract}
The hydrogenation of nitro compounds is an industrial process that has experienced a renovated interest in the last ten years due to the discovery of highly selective and environmentally friendly solid catalysts. Particularly, the performance of chemoselective reactions in the presence of very sensitive groups such as double and triple CC bonds, with $\mathrm{H}_{2}$ as reductant and no soluble additives needed, had been elusive for decades. The discovery that gold nanoparticles on solid supports could carry out such a reaction very selectively invigorated this area of research and claimed gold as an outstanding catalyst beyond oxidation processes. Subsequent work, devoted to understand how gold catalysts operate, established strong basis for the design of more efficient materials and the aperture of new routes for the synthesis of nitro derivatives. Here, we present three generations of materials that allowed improving the performance of the original gold catalysts. The relatively low activity of the initial $\mathrm{Au} / \mathrm{TiO}_{2}$ catalysts could be first boosted, without practical loss of selectivity, by the design of a material that incorporated two catalytic functions on the support: small amounts of platinum to enhance $\mathrm{H}_{2}$ dissociation, and a greater amount of gold to activate the $-\mathrm{NO}_{2}$ group. Later, we learnt how to control the catalytic structures and induce chemoselectivity to traditionally unselective metals such as platinum, ruthenium and nickel nanoparticles. Recently, $\mathrm{Fe}_{2} \mathrm{O}_{3}$ nanoparticles surrounded by a nitrogen-doped carbon layer have erupted as a promising alternative.A remarkable outcome from all that work is that the final pool of catalytic alternatives has been markedly expanded. Diversity is important because different solutions may open new gates to different catalytic processes, and we summarize here how the scope of new reactions and products could be expanded by means of properly designed metal catalysts in where support and metal work in a concerted way to direct the reaction toward the desired product. For example, whereas $\mathrm{Au} / \mathrm{TiO}_{2}$ is a chemoselective catalyst that drives the reaction efficiently to the fully reduced reaction product (aniline), the reaction could be tuned to obtain azocompounds in high yields by using nanoparticulated ceria to support the gold nanoparticles. On the other hand, whereas nitrobenzenes and aldehydes react in $\mathrm{H}_{2}$ to afford imines in the presence of $\mathrm{Au} / \mathrm{TiO}_{2}$, the product distribution can be switched toward a more oxidized condensation product (a nitrone) using a chemoselective $\mathrm{Pt} / \mathrm{C}$ catalyst, or to produce cyclohexanone oxime directly from nitrobenzene by means of supported $\mathrm{Au}$ and Pd metal catalysts. These and other examples represent some notable achievements, possibly, just the tip of the iceberg.
\end{abstract}

\section{Introduction}

Nitrogen is found in a variety of chemicals with industrial interest, within the fields of polymers, fertilizers, dyes, or biologically active compounds. ${ }^{1,2}$ Nitrogen is often integrated into these chemicals from $\mathrm{NH}_{3}$ (ammonolysis) or $\mathrm{HNO}_{3}$ (nitration) at the earliest reaction steps, and the resultant amines or nitro compounds, respectively, are primary building blocks in organic synthesis. The nitration route is particularly relevant to obtain nitroaromatic compounds and short nitroalkanes, because the selectivity toward the mono nitrated products is high following standard industrial protocols. From those, the production of amines by hydrogenation of the $-\mathrm{NO}_{2}$ group is a key transformation that has focused the attention of researchers for more than a century. ${ }^{1}$

In the last decade, a renewed interest in the hydrogenation of nitro compounds has awakened (Figure 
1) due to the discovery of metal catalysts that overcome the following long-lasting problems:

- It is difficult to reduce selectively nitro groups when other sensitive functions are present (the latter must often be retained to preserve products with high synthetic value).

- $\quad$ The preceding holds particularly true when $\mathrm{H}_{2}$ is the reducing agent (and $\mathrm{H}_{2}$ is the preferred industrial choice).

- It is difficult to control the nitro reduction to afford selectively the fully hydrogenated amine or, otherwise, a particular reduction intermediate, as desired.

- Getting high activity and selectivity is challenging, since increasing the activity often causes the selectivity to decrease.

- It is not trivial to accomplish all the above through an environmentally sustainable solid catalyst that does not require the use of soluble, often toxic, additives.

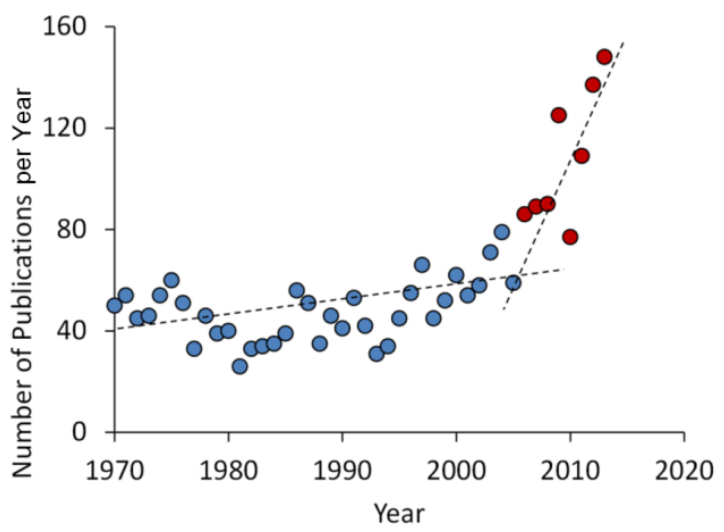

Figure 1. Number of publications per year before (blue squares) and after (red circles) the discovery of gold catalysts for the chemoselective hydrogenation of nitro compounds in 20064,13 (Web of Science Database, search criteria = "hydrogenation" \& "nitro").

We want to stress that reactions performed under hydrogen transfer conditions (using hydrazine, formic acid, or $\mathrm{NaBH}_{4}$, for instance) often result in a greater chemoselectivity toward the nitro reduction than when $\mathrm{H}_{2}$ is used directly. For instance, $\mathrm{Pd} / \mathrm{C}$, which is typically unselective for the hydrogenation of nitroalkenes with $\mathrm{H}_{2}$ (leading to aminoalkanes), catalyzes the formation of oximes in high yields with ammonium formate. ${ }^{3}$ Conversely, catalysts that are selective with $\mathrm{H}_{2}{ }^{4}$ are generally also selective under hydrogen transfer conditions. ${ }^{5,6,7}$ Some of these reducing agents are still common in laboratory-scale organic syntheses, but industry prefers $\mathrm{H}_{2}$ because it is readily available, cheap, and generates water as the reduction by-product.
Recently, $\mathrm{CO} / \mathrm{H}_{2} \mathrm{O}$ mixtures could be used to reduce nitrocompounds with gold catalysts. ${ }^{8,9}$

On the other hand, when referring to the chemoselective reduction of nitro compounds, the range of possibilities is broad, as it is the number of functional groups that may accompany the nitro group within the molecule. The accomplishment of high chemoselectivity is increasingly challenging as the reducibility of the competing functional group increases. For example, it is usually unnecessary to control the catalytic structures for achieving high selectivity with alkyl, hydroxy or alkoxy substituents, and most common industrial catalysts can be used upon proper selection of the reaction conditions. Similarly, halonitrobenzenes, and specially monosubstituted chloronitrobenzenes, may fall short for the identification of catalysts with genuine selectivity features, since an extensive list of catalysts has been shown to work suitably with those compounds. ${ }^{1}$ While this is consistent with the fact that chlorine is a rather poor leaving group, one can surprisingly see publications showing "first time" high selectivity for the hydrogenation of chloronitrobenzenes. ${ }^{10,11,12}$ In contrast, the number of catalysts that can hydrogenate nitro compounds selectively in the presence of $\mathrm{C}=\mathrm{C}, \mathrm{C} \equiv \mathrm{C}, \mathrm{C} \equiv \mathrm{N}$ or $\mathrm{C}=\mathrm{O}$ bonds, and that fulfill the series of requirements depicted above, is very limited. $\mathrm{C}=\mathrm{C}$ and $\mathrm{C} \equiv \mathrm{C}$ bonds are considered to be the biggest challenge, ${ }^{1}$ and most catalysts that are selective for the hydrogenation of chloronitrobenzenes fail when the substrate incorporates an olefinic group. $\mathrm{Au} / \mathrm{SiO}_{2}$ catalysts are good examples, since they are able to hydrogenate successfully chlorinated nitrobenzenes, nitrophenols, nitrotoluenes and alkoxy nitrobenzenes, ${ }^{13}$ but they are unselective for the hydrogenation of 3nitrostyrene. ${ }^{15}$ To reach chemoselectivity in the presence of $\mathrm{C}=\mathrm{C}$ and $\mathrm{C} \equiv \mathrm{C}$ bonds, Blaser el al used $\mathrm{Pb}$ or $\mathrm{H}_{3} \mathrm{PO}_{4}$ to tweak the performance of supported platinum nanoparticles, and cleverly added vanadium and iron salts to avoid the accumulation of partially reduced nitro compounds. ${ }^{1}$ Thinking in a more sustainable process, we developed a series of alternatives that do not require toxic additives in solution to achieve an optimal, broadspectrum performance, $4,14,15,16,17,18,19,20,21$ and today rather general chemoselective catalysts can be accomplished with gold, ${ }^{4}, 22$ platinum, ${ }^{17}$ ruthenium, ${ }^{17}$ nickel ${ }^{17}$ and, more recently, iron, ${ }^{23}$ silver, ${ }^{24}$ and rhodium. ${ }^{25}$

Here, we will summarize our contribution to the various generations of heterogeneous catalysts developed in the last ten years for the chemoselective hydrogenation of substituted nitrocompounds, and a series new reaction processes that were derived from them to synthesize useful organic precursors.

\section{First Generation: Gold Catalysts} 2.1. Discovery of Chemoselective Gold Catalysts. We found that nitrobenzene was being reduced to aniline at $423 \mathrm{~K}$ in the presence of styrene, dimethylformamide (DMF) and $\mathrm{Au} / \mathrm{TiO}_{2}$. It turned out that, in the presence of 
small amounts of water within the reactants, hydrolysis of DMF to formic acid (and dimethylamine) occurred, with the former acting as a hydrogen donor. Interestingly, styrene in the solution remained intact. When we used formic acid directly as the reducing agent, at a lower temperature $(313 \mathrm{~K})$, it was confirmed that $\mathrm{Au} / \mathrm{TiO}_{2}$ can hydrogenate selectively nitrocompounds without altering $\mathrm{C}=\mathrm{C}, \mathrm{C}=\mathrm{O}$ or $\mathrm{C} \equiv \mathrm{N}$ substituents. In contrast, conventional platinum or palladium supported nanoparticles led to mixtures of products in where each functional group was indistinctly reduced. At that point, the question was if gold could perform that chemoselective hydrogenation with $\mathrm{H}_{2}$ instead of formic acid as the reducing agent. The designed isotopic and kinetic experiments clearly showed that $\mathrm{Au} / \mathrm{TiO}_{2}$ (and $\mathrm{Au} / \mathrm{Fe}_{2} \mathrm{O}_{3}$ ) were not only able to dissociate $\mathrm{H}_{2}$ for the $-\mathrm{NO}_{2}$ hydrogenation, but that anilines incorporating a variety of substituents (including $\mathrm{C}=\mathrm{C}$ and $\mathrm{C} \equiv \mathrm{C}$ bonds) could be obtained in high yields from the corresponding nitro compounds (Figure 2).

2.2. Elucidation of the Catalyst Specificity. To understand the mode of action of gold catalysts, kinetic measurements, IR spectroscopy, and DFT theory were combined to elucidate how molecules such as nitrobenzene, styrene (or mixtures of them), and nitrostyrene interact with the surface of various (supported and unsupported) gold catalysts. The in silico calculations suggested that both $\mathrm{C}=\mathrm{C}$ and $-\mathrm{NO}_{2}$ groups interact similarly (weakly) with the surface of the (bare) gold nanoparticles, ${ }^{15}$ leading to unselective catalysis. In agre

eme

nt

with

the

theo

retic

al

calc

ulati

ons, gold nanoparticles on inert supports such as $\mathrm{SiO}_{2}$ or carbon were shown unselective for the hydrogenation of nitrostyrene in batch experiments. ${ }^{15}$ Theory, moreover, predicted that the adsorption of the $-\mathrm{NO}_{2}$ group should prevail over the adsorption of the $\mathrm{C}=\mathrm{C}$ bond, with an optimal adsorbate/absorbent interaction for catalysis, when the reaction was simulated to occur at the interface between gold and a $\mathrm{TiO}_{2}$ support, providing the first stone towards the understanding of the catalytic mode of action. ${ }^{15}$ IR spectroscopy demonstrated empirically that the interaction of nitrobenzene with gold catalysts is strong and hinders the adsorption of other molecules containing $\mathrm{C}=\mathrm{C}$ bonds (such as styrene) when the support is $\mathrm{TiO}_{2}$, but not when the support is $\mathrm{SiO}_{2} \cdot{ }^{15}$ In parallel, kinetic experiments showed that the rate of the nitrobenzene hydrogenation by $\mathrm{Au} / \mathrm{TiO}_{2}$ is greater than that of styrene. This was even more so when both substrates were reacted together. ${ }^{15}$ All the above results revealed that the high chemoselective of $\mathrm{Au} / \mathrm{TiO}_{2}$ catalysts should be attributed to a metal/support interface that regulates the adsorption phenomena in favor of a preferential activation of the $-\mathrm{NO}_{2}$ group. Interestingly, it has been recently shown that unsupported gold nanoparticles are inactive for the hydrogenation of the $\mathrm{NO}_{2}$ group of 4-nitrobenzaldehyde, but able to reduce the carbonyl group to an alcohol in the presence of $\mathrm{H}_{2}$ and a base. ${ }^{26}$

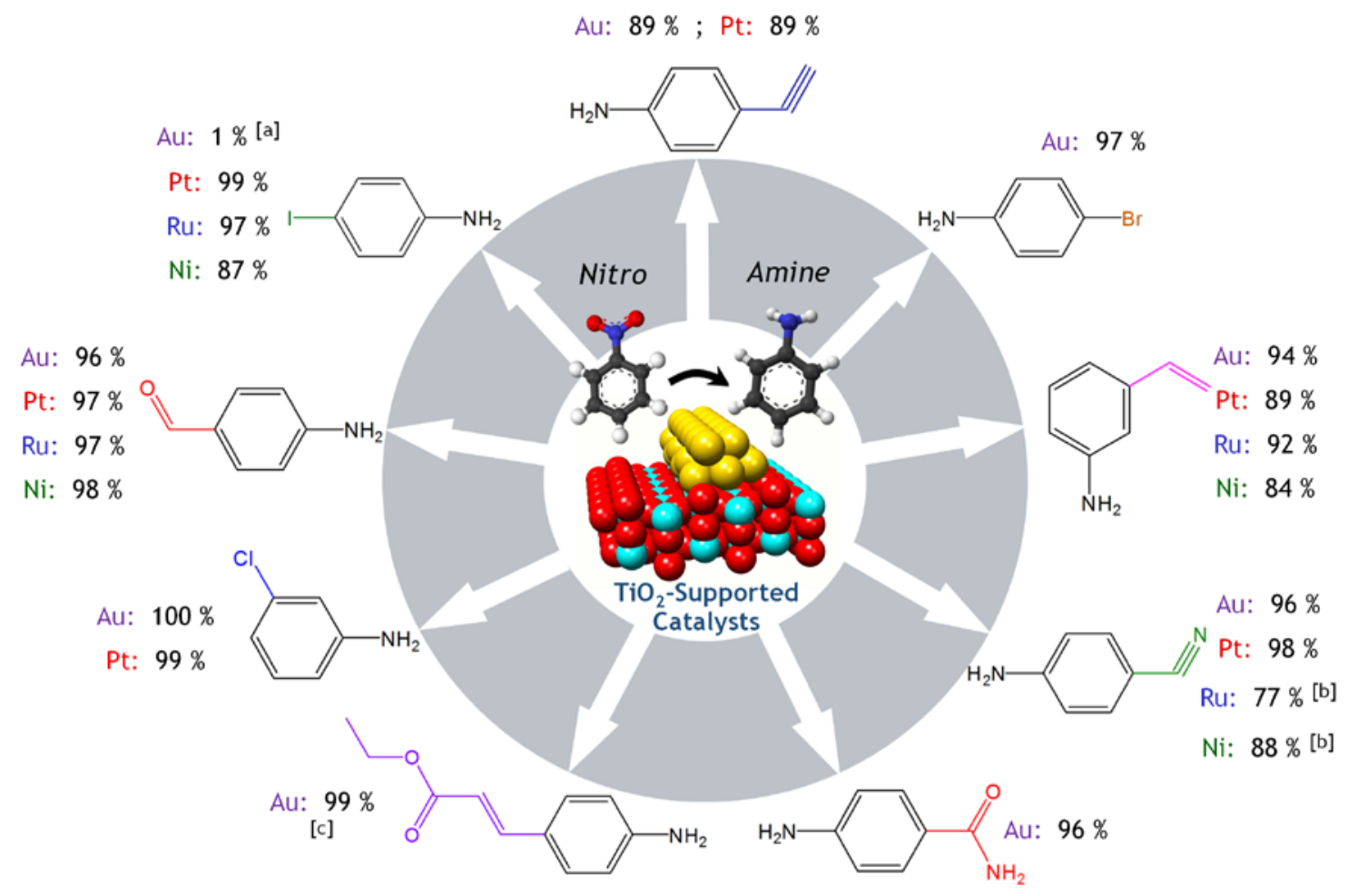


Figure 2. Scope of substituted anilines synthesized by hydrogenation of the corresponding nitro compounds with metal nanoparticles supported on $\mathrm{TiO}_{2}$. Yields (\%) are displayed. To achieve optimal performance $\mathrm{Pt} / \mathrm{TiO}$, $\mathrm{Ru} / \mathrm{TiO}_{2}$, and Ni/TiO${ }_{2}$ must be reduced in $\mathrm{H}_{2}$ at $723 \mathrm{~K}$ before reaction to promote a Strong Metal-Support Interaction. See experimental details in4,17 [a] Low yield due to low catalytic activity. [b] Loss of yield due to hydrolysis of the nitrile group. [c] Unpublished results from our laboratory.

2.3. The Nitro into Amine Transformation Path on Supported Gold Catalysts. Another interesting feature of $\mathrm{Au} / \mathrm{TiO}_{2}$ catalysts is that aniline is practically the only product detected in the liquid phase during the hydrogenation of the nitrocompound, independently of the conversion. ${ }^{16}$ The $\mathrm{Au} / \mathrm{TiO}_{2}$ catalyst, thus, avoids the accumulation of partially reduced intermediates, unlike other chemoselective alternatives that required soluble metal salts as co-catalysts for similar purposes. ${ }^{1}$ Notwithstanding, the nitro into amine transformation must still proceed through a series of elemental steps, as formerly proposed by Haber (Figure 3).

We used operando IR spectroscopy to characterize the $\mathrm{H}_{2}$ and nitrobenzene. ${ }^{16}$ The spectra evidenced the formation of nitrosobenzene, phenylhydroxylamine and aniline on the catalyst surface and excluded azobenzene, azoxybenzene and hydrazobenzene as potential reaction intermediates. ${ }^{16}$ Accordingly, it was inferred that the $\mathrm{NO}_{2}$ into $-\mathrm{NH}_{2}$ transformation occurs on $\mathrm{Au} / \mathrm{TiO}{ }_{2}$ catalysts through the Direct Reaction Route depicted in Figure 3. Equivalent conclusions were later reached with $\mathrm{Au} / \mathrm{Al}_{2} \mathrm{O}_{3}$ catalysts. ${ }^{23}$ Additional batch experiments with $\mathrm{Au} / \mathrm{TiO}_{2}$ catalysts showed that whereas the accumulation of intermediates in the liquid phase is avoided when nitrobenzene is used as the only starting reactant, large amounts of condensation products are formed if the reaction feed includes both nitro and nitrosobenzene. ${ }^{16}$ From these results, it was concluded that the nitrosobenzene intermediate detected by IR spectroscopy must be strongly retained onto the catalyst surface during a batch reaction experiment because, if it was not so, one should observe an accumulation of condensation intermediates in the solution. Moreover, with $\mathrm{TiO}_{2}$ as support, the surface concentration of nitrosobenzene was found to be relatively low, minimizing the surface bimolecular nitroso/hydroxylamine interactions, and so species formed on the $\mathrm{Au} / \mathrm{TiO}_{2}$ surface in the presence of

the formation of condensation intermediates (Figure 3).

Figure 3. Reaction route proposed by Haber for the hydrogenation of nitroaromatic compounds. Names below each structure refer to the prefix that identifies the nitrogen functional group.

Interestingly, recent results have demonstrated that the nitro hydrogenation reaction route on gold catalysts is support dependent. Ceria, in contrast to $\mathrm{TiO}_{2}$, favors the Condensation Route 27,28 , and when the catalyst was optimized it was possible to achieve very high yields of relevant azocompounds. This result has been explained by assuming that with $\mathrm{Au} / \mathrm{CeO}_{2}$ a greater concentration of nitrosobenzene is generated on the catalyst surface. ${ }^{28}$ Thus, an efficient protocol for the synthesis of azocompounds was discovered, ${ }^{28}$ as depicted more in detail below.

2.4. An Activity Issue ... Gold was soon featured as a promising, versatile catalyst for the chemoselective hydrogenation of nitro compounds, ${ }^{29}$ but its activity should be improved for a potential industrial application. To do that, a thorough kinetic investigation with $\mathrm{Au} / \mathrm{TiO}_{2}$ catalysts for the hydrogenation of nitrobenzene with $\mathrm{H}_{2}$ was performed to identify the rate-determining reaction step during the reduction of nitrocompounds. The reaction rate was observed to decrease with increasing nitrobenzene concentrations in the range $0.2-1.2 \mathrm{mmol} / \mathrm{L}$ at $393 \mathrm{~K}$ and 8 bar of $\mathrm{H}_{2}$ in toluene, whereas the dependence was direct, and linear, with the $\mathrm{H}_{2}$ pressure when the nitrobenzene concentration was held constant at $\sim 0.42 \mathrm{mmol} / \mathrm{L}$. Assuming Langmuir-Hinshelwood and Hougen-Watson hypotheses, the experimental data could be satisfactorily reproduced with a kinetic model that assumes the dissociation of $\mathrm{H}_{2}$ as the rate-determining step.

To further check this model, we designed a series of $\mathrm{Au} / \mathrm{TiO}_{2}$ catalysts with variable sizes of the gold nanoparticles, ${ }^{30}$ taking into account the following

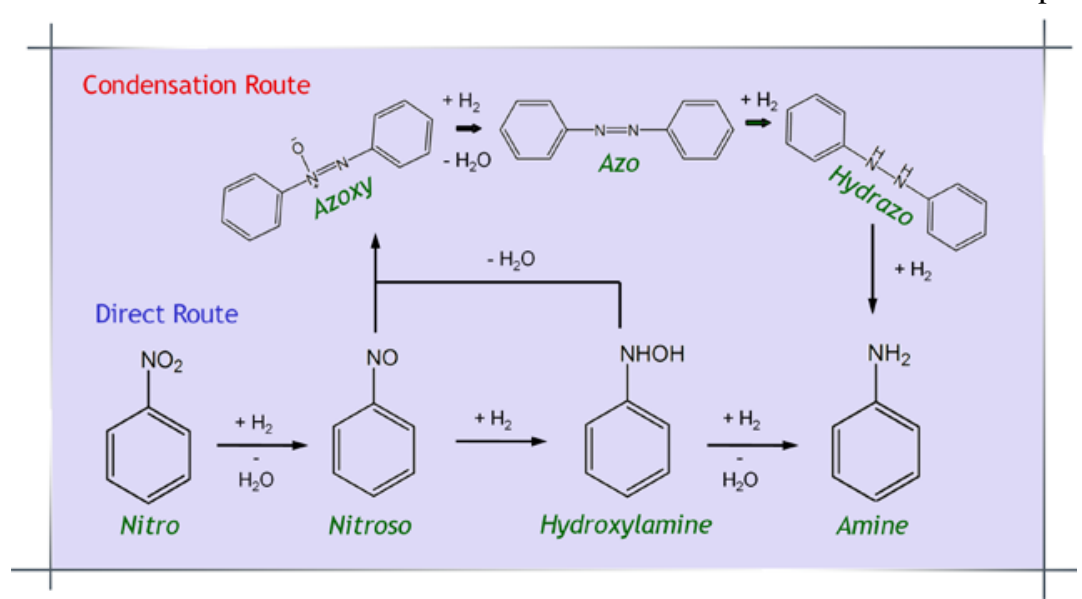
observations: a) the activity of gold for $\mathrm{H}_{2}$ dissociation is correlated with the number of low coordination sites in the metal nanoparticle; ${ }^{31}$ and b) the number of low coordinated sites depends, at least in part, on the gold particle size. ${ }^{32}$ We quantified the number of low coordination gold species in this 
series of catalysts using IR spectroscopy and $\mathrm{CO}$ as a probe molecule. A direct correlation between the total number of low coordinated zero-valent gold centers and the activity for $\mathrm{H}_{2}$ dissociation, measured by $\mathrm{H}_{2} / \mathrm{D}_{2}$ exchange, was found. Furthermore, and more importantly, catalysts activating $\mathrm{H}_{2}$ fastest were also the most active in the hydrogenation of nitrocompounds, ${ }^{21}$ in agreement with the kinetic model inferred. ${ }^{20}$

Thus, to increase the catalytic activity of $\mathrm{Au} / \mathrm{TiO}_{2}$, one should control the gold nanoparticles architecture to increase the number of low coordination metal centers. We noted, however, that the increase in activity that can be achieved through this synthetic strategy is limited..$^{21,33}$ Thus, we had to find other ways to increase the activity of the catalyst.

\section{Second Generation: Bimetallic Gold/Platinum Catalysts.}

Prompted by the realization that a) the hydrogenation of nitrocompounds by gold is limited by $\mathrm{H}_{2}$ dissociation and b) other metals such as platinum dissociate $\mathrm{H}_{2}$ readily, we envisioned the use of $\mathrm{TiO}_{2}$-supported bimetallic platinum-gold formulations as a promising strategy to improve previous results. Since it was found that the reaction controlling step was $\mathrm{H}_{2}$ dissociation, we thought that by adding small amounts of $\mathrm{Pt}$ to the $\mathrm{Au} / \mathrm{TiO}_{2}$ catalyst, the rate of the reaction, i.e. of $\mathrm{H}_{2}$ dissociation, could be increased. Meanwhile, for such a small $\mathrm{Pt}$ content, no effect on selectivity might occur. Then, we investigated the influence of increasing amounts of platinum, from 50 to $2000 \mathrm{ppm}$ on the $\mathrm{Au} / \mathrm{TiO}_{2}$ catalyst, on the activity and selectivity for the hydrogenation of 3nitrostyrene and found that the addition of $100 \mathrm{ppm}$ of $\mathrm{Pt}$ is sufficient to promote a $\sim 8$-fold increase in activity of our most active $\mathrm{Au} / \mathrm{TiO}_{2}$ catalysts at $358 \mathrm{~K}$, with little formation of undesired by-products (93.4\% selectivity to 3-vinylaniline at $\sim 95 \%$ conversion). Higher Pt contents led to gradually higher activity, but with a gradually lower chemoselectivity. Meanwhile, catalysts with no gold and $100 \mathrm{ppm}$ of $\mathrm{Pt}$ on $\mathrm{TiO}_{2}$ gave negligible conversion, ${ }^{20}$ stressing the bifunctional character of the $\mathrm{Au}-\mathrm{Pt}$ formulation. The bifunctional $\mathrm{Au}-\mathrm{Pt} / \mathrm{TiO}_{2}$ catalyst offers additional advantages over the original $\mathrm{Au} / \mathrm{TiO}_{2}$ catalysts such as lower separation costs and greater productivity through reactions performed in the absence of a solvent (nitro/Au mol ratio $=6738) .{ }^{20}$ Interestingly, the conversion vs time curve with the bimetallic material show a nearly constant slope to conversions up to $90 \%$, suggesting that the deactivation of the catalyst after almost 7000 turnovers is insignificant. $\mathrm{Au} / \mathrm{TiO}_{2}$ catalysts in the absence of trace amounts of $\mathrm{Pt}$, in contrast, only achieve $\sim 1350$ turnovers and suffer from evident deactivation when the reaction is performed free of a solvent. $^{20}$
Recently, similar bimetallic Au-Pt formulations have been proposed for the hydrogenation of less demanding, from the chemoselectivity standpoint, nitroaromatics that incorporate $-\mathrm{Cl}^{34}$ and $-\mathrm{OH} .{ }^{35}$ Whether or not these investigations bring any advantage is difficult to evaluate, because of the lack of cross-references to earlier work. With monochlorinated nitrocompounds, other metals, such as $\mathrm{Pd}$, can also be selective $\left(\mathrm{Pd}-\mathrm{Au} / \mathrm{Al}_{2} \mathrm{O}_{3}\right.$, with a 1:20 mol ratio). ${ }^{36}$

\section{Third Generation: Platinum, Ruthenium and Nickel Catalysts}

4.1. The Role of the Metal Nanoparticle Architecture. To expand the scope of chemoselective catalysts for the hydrogenation of nitrocompounds, we next focused on the design of methods that could transform highly active, but traditionally unselective metals into highly chemoselective catalysts. ${ }^{17}$

The effect of the active sites architecture on the hydrogenation of either styrene or nitrobenzene was firstly investigated through $\mathrm{Pt} / \mathrm{Al}_{2} \mathrm{O}_{3}$ catalysts with variable metal content (0.2-5 wt \%). ${ }^{17}$ On average, particle size increased when the metal content was increased. ${ }^{17}$ Complimentary, IR spectra of the catalysts probed with $\mathrm{CO}$ showed that the fraction of atoms in extended platinum terraces increases with the metal loading, ${ }^{17}$ consistent with nanoparticles that are, on average, larger. In the catalytic experiments, styrene reduced faster ( $\mathrm{mol}$ converted $\times$ total mol of $\mathrm{Pt}^{-1} \times \mathrm{h}^{-1}$ ) as the average platinum particle size and the number of terrace platinum sites increased. The particle size effect was, in contrast, minor on the nitrobenzene hydrogenation rate. In agreement, $\mathrm{Pt} / \mathrm{Al}_{2} \mathrm{O}_{3}$ catalysts with the lowest platinum contents provided the greatest selectivities in the hydrogenation of 3-nitrostyrene (65\%, at almost complete conversions), whereas catalysts with the highest contents (5 wt \%) produced 3-vinylaniline with a selectivity $<25 \% .{ }^{17,21}$ The selectivity to 3 -vinylaniline could be increased $(\sim 91 \%$ at $95 \%$ conversion) by the design of a catalyst that virtually lacked platinum terrace sites accessible to the reactants, using a high area mesoporous active carbon as the support. ${ }^{37}$ A similar effect is achieved by capping the surface of the metal nanoaparticles with strongly bonded organic thiol ligands. ${ }^{38}$ Interestingly, the performance/structure dependence just depicted for nitro groups competing with $\mathrm{C}=\mathrm{C}$ bonds in nitrostyrenes is reversed, and much less intense, for chloronitrobenzenes, where the selectivity decreases from $96.4 \%$ to $84.5 \%$ when the particle size decreases from $\sim \mathbf{1 2 . 2} \mathrm{nm}$ to $\sim \mathbf{1 . 9}$ $\mathrm{nm} .{ }^{39}$ The advantage of Pt with respect to gold is that owing to the high activity for $\mathrm{H}_{2}$ dissociation, the reactions could be performed under conditions where gold is virtually inactive ( $313 \mathrm{~K}$ and $2 \mathrm{bar}$, in toluene).

Recently, impressive molecular engineering has been accomplished to synthesize Pt single-atom centers and very tiny Pt clusters on iron oxide supports, which are 
shown highly active, selective and of general use in the hydrogenation of nitroaromatics. ${ }^{40}$

4.2. The Role of Strong Metal Support Interactions. We observed that properly prepared $\mathrm{Pt} / \mathrm{C}$ catalysts can catalyze the reduction of nitroaromatic compounds selectively, but they suffer from a main drawback: up to $25 \%$ phenylhydroxylamine intermediates form during the reaction ${ }^{17}$-and these species are associated with a loss in product quality. ${ }^{\text {The }}$ problem was circumvented by selection of $\mathrm{TiO}_{2}$ as the support, considering that: a) $\mathrm{TiO}_{2}$ in $\mathrm{Au} / \mathrm{TiO}_{2}$ catalysts is key for avoiding the accumulation of reaction intermediates; ${ }^{16}$ b) $\mathrm{TiO}_{2}$ in $\mathrm{Au} / \mathrm{TiO}_{2}$ is key to boost the chemoselectivity;15 and c) terrace platinum sites, detrimental to selectivity, ${ }^{17}$ can be blocked by $\mathrm{TiO}_{\mathrm{x}}$ species from the support due to strong metal support interaction phenomema at high activation temperatures. ${ }^{41}$ Strong metal-surface interactions are often invoked as critical in

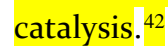

HRTEM and EELS evidenced the presence of $\mathrm{TiO}_{x}$ patches on top of $\mathrm{TiO}_{2}$-supported platinum nanoparticles reduced at $723 \mathrm{~K}$ in $\mathrm{H}_{2}$, and IR spectroscopy demonstrated the absence of terrace sites accessible to small reactants, such as $\mathrm{CO}^{17}$ The selectivity to 3-vinylaniline (from 3nitrostyrene) was then $93 \%$ at $95 \%$ conversion, a result that drastically differs from the low selectivities observed for $\mathrm{Pt} / \mathrm{TiO}_{2}$ catalysts activated at $473 \mathrm{~K}$ that are not decorated with $\mathrm{TiO}_{x}$ species (i.e. $5 \%$ to 3-vinylstyrene at $90 \%$ conversion). ${ }^{21}$ Moreover, in contrast to the chemoselective $\mathrm{Pt} / \mathrm{C}$ catalyst depicted above, the accumulation of reaction intermediates with the decorated $\mathrm{Pt} / \mathrm{TiO}_{2}$ catalyst was avoided. Previous reports had shown a positive effect of the catalyst decoration in the selectivity of $\mathrm{Pt} / \mathrm{TiO}_{2}$ for the hydrogenation of $p$ chloronitrobenzene, but this was, comparatively, insignificant (corresponding to a difference of $97.7 \mathrm{vs}$. 99.3 \%). ${ }^{43}$ The effect of the $\mathrm{TiO}_{\mathrm{x}}$ decoration on the nitro group activation with regard to a $\mathrm{C}=\mathrm{C}$ bond is overwhelming: the former makes the styrene hydrogenation rate to fall two orders of magnitude when present together with nitrobenzene in a 1:1 mol ratio. ${ }^{21}$ Recent investigations have shown that the decoration of $\mathrm{Pt}$ nanoparticles with $\mathrm{Zn}$ species in $\mathrm{Pt} / \mathrm{ZnO}$ catalysts leads to a similar increase in the catalyst selectivity. ${ }^{44}$

In a subsequent series of experiments, the generality of the decoration concept was demonstrated through catalysts that included other metals such as ruthenium and nickel. With this battery of alternatives, a broad range of substrates containing $\mathrm{C}=\mathrm{C}, \mathrm{C} \equiv \mathrm{C}$, iodine, chlorine, bromide, cinnamate, nitrile, and carbonyl substituents could be satisfactorily tackled (Figure 1) ${ }^{17}$ More recently, silver-cerium oxide core-shell nanoparticles have been also shown highly active and selective for the hydrogenation of a number of nitrostyenes. ${ }^{24}$

\section{New Synthetic Opportunities}

The discovery of new chemoselective catalysts brought back some old processes that were left behind due to unsatisfactory performance, while opened the door to new synthetic reaction routes. A series of illustrative examples will be described below.

5.1. Synthesis of Oximes. Oximes may be obtained from $\alpha, \beta$-unsaturated nitro compounds provided that the catalyst is able to avoid a parallel hydrogenation of the $\mathrm{C}=\mathrm{C}$ bond and a consecutive hydrogenation of the desired $-\mathrm{C}=\mathrm{NOH}$ group. $\mathrm{Au} / \mathrm{TiO}_{2}$ was such a catalyst that could produce oximes in high yields from conjugated nitroalkenes, which may also include functionalities such as $\mathrm{Br},-\mathrm{OCH}_{3}$ or $-\mathrm{NO}_{2}$. For example, 2-nitrophenyl acetaldehyde oxime was formed with $96 \%$ selectivity from $\beta, 2$-dinitrostyrene at $95 \%$ conversion on $\mathrm{Au} / \mathrm{TiO}_{2}$, whereas commercial $\mathrm{Pd} / \mathrm{C}$ and $\mathrm{Pt} / \mathrm{C}$ catalysts provided yields $<1 \% .{ }^{17}$ The method could be applied to produce cyclohexanone oxime, a 5 million metric-ton product used to manufacture Nylon 6, in high yields from 1-nitro1-cyclohexene $\left(\sim 91 \%\right.$ at $383 \mathrm{~K}$ and 15 bar of $\mathrm{H}_{2}$, see Figure $4 \mathrm{~B}) .{ }^{4,18}$. Industrially, cyclohexanone oxime is obtained by ammoximation of cyclohexanone, whereby ciclohexanone is obtained by air oxidation of cyclohexane at $\sim 8 \%$ conversion per pass, and hydroxylamine has to be used or, otherwise, synthesized in situ with $\mathrm{H}_{2} \mathrm{O}_{2}$ in $\mathrm{NH}_{4}$ (aq.) as it is done in the Sumitomo-ENI process (Figure $4 \mathrm{~A})$.

Later, it was found that $\mathrm{Pt} / \mathrm{TiO}_{2}$ catalysts could efficiently afford cyclohexanone oxime from nitrocyclohexane with the $\mathrm{TiO}_{\mathrm{x}}$-decorated platinum catalysts. ${ }^{45}$ This process was previously performed by DuPont and $70 \%$ yields were achieved with a PbO-modified Pd catalyst, at $413 \mathrm{~K}$ and 35 bar. ${ }^{46}$ Yields up to $80 \%$ were achieved under solvent-free conditions (>1300o turnovers) at $353 \mathrm{~K}$ and 4 bar of $\mathrm{H}_{2}$ with the decorated $\mathrm{Pt} / \mathrm{TiO}_{2}$ catalyst doped with $\mathrm{Na}$ to avoid Lewis catalyzed side reactions. ${ }^{45} \mathrm{Au} / \mathrm{Al}_{2} \mathrm{O}_{3}$ was later shown to work for this reaction with yields to the oxime of $\sim 83 \%$ at $373 \mathrm{~K}$ and 6 bar in ethanol (o.33 mol nitrocyclohexane/L). ${ }^{47}$
A

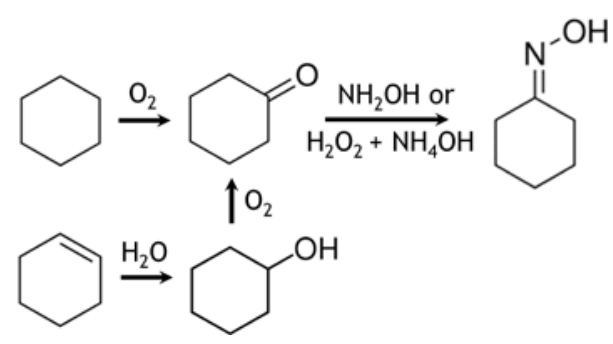

B

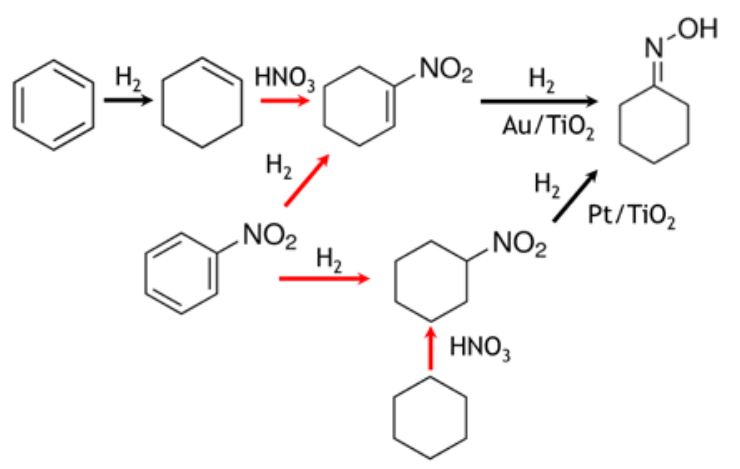




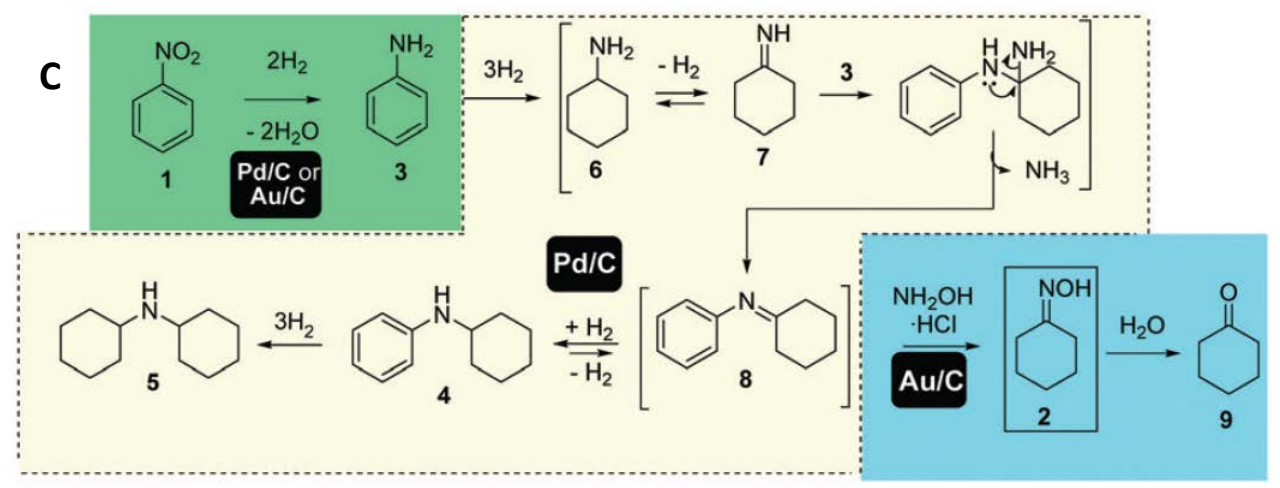

Figure 4. Some representative methods for the synthesis of cyclohexanone oxime. Current industrial approaches are based on oxidative paths from cyclohexane or cyclohexene (A). Promising alternatives arise due to new catalysts for the selective hydrogenation of nitrocyclohexene ${ }^{4}$ or nitrocyclohexane ${ }^{45}$ (B), or nitrobenzene ${ }^{48}$ (C). Red arrows in B denote steps that require discovery or notable improvement of existing catalytic technology.

5.2. Direct Synthesis of Cyclohexanone Oxime From Nitrobenzene. The limitation of the procedures described above to synthesize cyclohexanone oxime is the requirement to prepare 1-nitro-1-cyclohexene or nitrocyclohexane. Then, we have recently developed a single-step procedure, involving $\mathrm{Au} / \mathrm{C}$ and $\mathrm{Pd} /$ catalysts in the presence of $\mathrm{NH}_{2} \mathrm{OH} \cdot \mathrm{HCl}$ and $\mathrm{H}_{2}$ at $333 \mathrm{~K}$, where cyclohexanone oxime can be obtained directly from nitrobenzene (Figure $4 \mathrm{CC}){ }^{48}$ In this process, cyclohexylamine and aniline are formed first by hydrogenation on either Pd or Au centers. The former two subsequently condense into an imine catalyzed by Pd, with gold next acting as a Lewis acid ${ }^{49}$ to catalyze the imine hydrolysis to cyclohexanone. Finally, in the presence of $\mathrm{NH}_{2} \mathrm{OH} \cdot \mathrm{HCl}$, cyclohexanone oxime is formed in high yields (97\%) through an efficient cascade-type reaction.

5.3. Synthesis of Aromatic Azocompounds in One Step. Azocompounds could recently be synthesized directly from nitroaromatics using $\mathrm{Au} / \mathrm{CeO}_{2}$ catalysts. ${ }^{27,28}$ These compounds are widely used as dyes, food additives and drugs. Only up to $15 \%$ selectivity to azobenzene was achieved with a low area ceria, ${ }^{27}$ which was increased to > $95 \%$ with nanoparticulated $\mathrm{CeO}_{2}{ }^{28}$ Kinetic and IR data evidenced that the conversion of nitrosobenzene to the corresponding hydroxylamine is with this catalyst relatively slow, leading to high concentration of nitrosobenzene on the catalyst surface. ${ }^{28}$ In this scenario, nitrosobenzene and the corresponding hydroxylamine condense before further hydrogenation to aniline occur, forming azoxybenzene and, subsequently, azobenzene.
These results contrast to those obtained when the support was $\mathrm{TiO}_{2}$ (Figure 5). ${ }^{16}$ Azocompounds can be obtained in high yields not only because the Condensation Route is favored when $\mathrm{CeO}_{2}$ is the support, but also because the undesired hydrogenation of the azo group to aniline is inhibited in the presence of even traces of azoxybenzene. ${ }^{16,28}$ Therefore, by using a gold catalyst on a high surface area $\mathrm{CeO}_{2}$ it is possible now to produce azocompounds in one step with very high yields.

\subsection{Cascade Type Reactions: One-Step Synthesis of} Imines, Secondary Amines, Nitrones, and $\beta$-Amino Carbonyls. Amines are ubiquitous precursors to lend new $\mathrm{N}-\mathrm{C}$ bonds by condensation with a second functionality. Thanks to the discovery of chemoselective catalysts for the hydrogenation of nitrocompounds, we can now conceive single-step processes that combine several cascade reactions (among others, a full or partial reduction of the nitro group). Cascade-type reactions are interesting because they allow the design of more intensive process, increase the atom-economy and are, thus, more ecofriendly.

For example, $\mathrm{Au} / \mathrm{TiO}_{2}$ catalysts were used to obtain imines with good yields (8o-87 \%) directly from nitroaromatic compounds, aldehydes and $\mathrm{H}_{2}$ in a single reaction step (Figure 6), even when sensitive substituents such as $\mathrm{C}=\mathrm{C}$ bonds or $\mathrm{Br}$ were present. ${ }^{19}$ Substituted imines are important building blocks in the synthesis of fine chemicals, pharmaceutical compounds, and 
agrochemicals. $^{50}$ The results lie on a catalyst that facilitates full reduction of the nitro group into an amine without reduction of the $-\mathrm{C}=\mathrm{O}$ bond and the rest of functionalities. Secondary amines could also be obtained in high yields by simple prolongation of the reaction time; and aldehydes incorporation conjugated $\mathrm{C}=\mathrm{C}$ bonds led to $\alpha, \beta$-unsaturated imines, whereas $\alpha, \beta$-unsaturated ketones yielded $\beta$-amino carbonyl compounds. ${ }^{19}$

We could drastically tune the distribution of reaction products in mixtures of nitrocompounds, aldehydes and $\mathrm{H}_{2}$ by using a different chemoselective catalyst, mesoporous carbon-supported platinum nanoparticles, opening the possibility to obtain another valuable class of building blocks for organic syntheses: nitrones. This cascade reaction requires not only a chemoselective catalyst, but that the aldehyde condenses with the hydroxylamine intermediate before the nitro group is fully reduced to an amine. The $\mathrm{Pt} / \mathrm{C}$ catalyst depicted hereinabove, which lacks platinum terrace sites accessible to the reactants, can do this reaction very efficiently, with yields to a variety of substituted nitrones that can exceed $90 \%$ (Figure 6). ${ }^{51}$ Common supported platinum catalysts, in contrast, were found unselective.

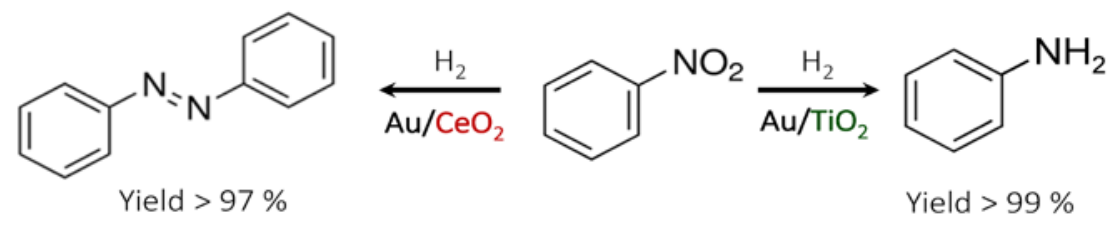

Figure 5. Influence of the support in the distribution of products during the hydrogenation of nitrobenzene. On $\mathrm{TiO}_{2}$, gold nanoparticles catalyze a full reduction of the nitro group, ${ }^{4}$ whereas azocompounds form in high yields when the support is nanoparticulated $\mathrm{CeO}_{2}{ }^{28}$

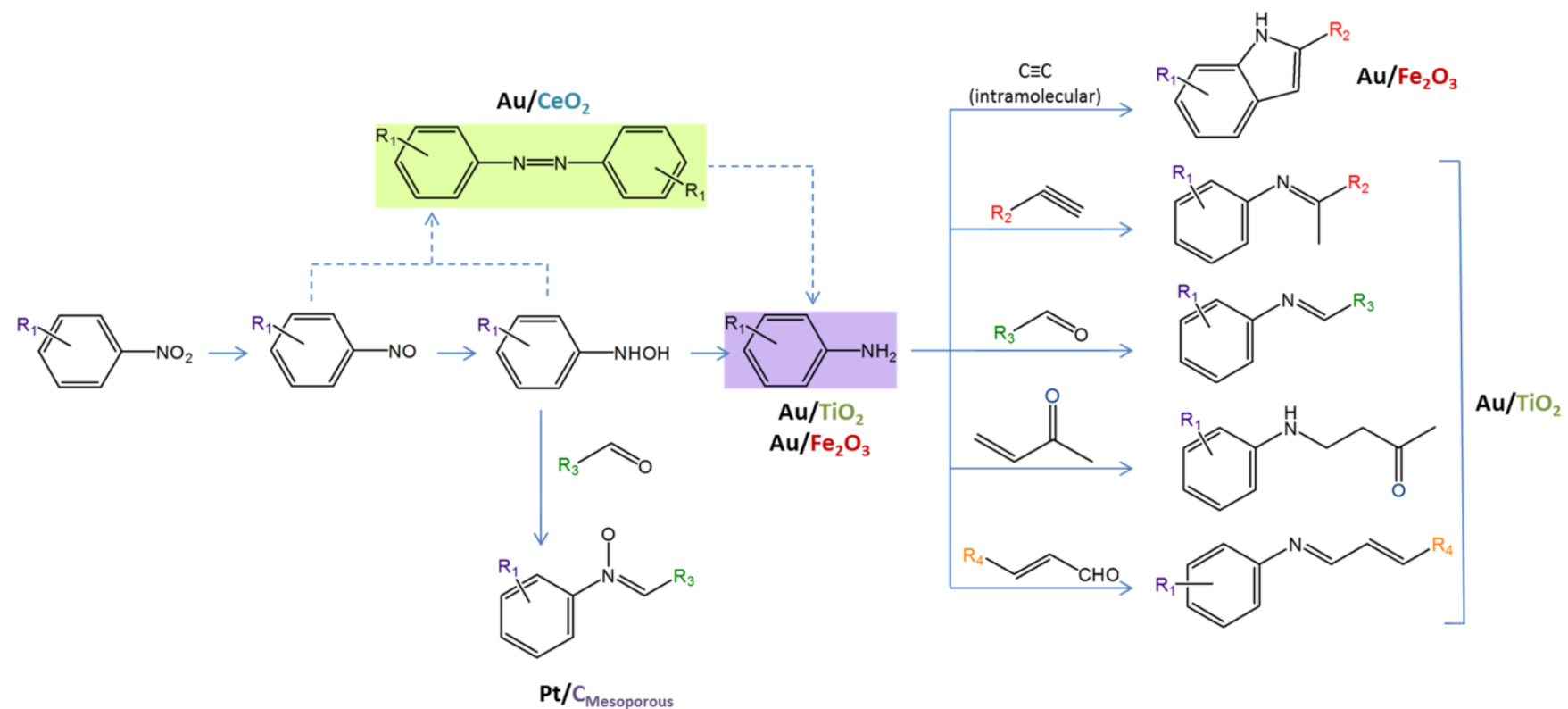

Figure 6. A diversity of chemicals can be obtained from nitro compounds via single-step reactions thanks to the development of a variety of catalysts that hydrogenate the $-\mathrm{NO}_{2}$ chemoselectively in the presence of other reactive functionalities.

On the other hand, $\alpha, \beta-$ Unsaturated ketones could also be engaged in cascade-type processes with anilines synthesized in situ from nitro compounds. In this case, the addition reaction takes place through the conjugated $\mathrm{C}=\mathrm{C}$ bond to produce $\beta$-amino carbonyls in good yields $(83-91 \%)$ in the presence of $\mathrm{Au} / \mathrm{TiO}_{2} \cdot{ }^{19}$ The support plays a 
dual role here: a) induces chemoselectivity and b) supplies Lewis acid sites for the addition reaction, ${ }^{19}$ and the tolerance to ligands such as ethyl cinnamates or nitriles opens the door to important fragrances and biocides. ${ }^{52}$ The $\mathrm{Au} / \mathrm{TiO}_{2}$ sample, moreover, catalyzes the three-component reaction between nitrobenzenes, phenylacetylenes, and $\mathrm{H}_{2}$ to methyl substituted imines. ${ }^{19}$ Gold acts in this case as a catalytically active species both for reduction of the $-\mathrm{NO}_{2}$ group to $-\mathrm{NH}_{2}$ and for the subsequent coupling between the amine and the $\mathrm{C} \equiv \mathrm{C}$ group. ${ }^{53} \mathrm{Au} / \mathrm{Fe}_{2} \mathrm{O}_{3}$ has also been used in inter and intramolecular tandem reactions between nitro compounds and $\mathrm{C} \equiv \mathrm{C}$ to form indoles. ${ }^{54}$

$\mathrm{N}$-alkylated anilines could be also obtained from nitrobenzenes and alcohols on $\mathrm{Au} / \mathrm{Fe}_{2} \mathrm{O}_{3}$, in a process where gold catalyzes oxidation of the hydroxyl group into aldehyde via formation of $\mathrm{Au}-\mathrm{H}$ species that cause reduction of the $-\mathrm{NO}_{2}$ group into $-\mathrm{NH}_{2}$, with final formation of the imine upon amine/aldehyde condensation. ${ }^{55}$

Recently, $\mathrm{MgO}$, a solid base, and a chemoselective $\mathrm{Pt} / \mathrm{TiO}_{2}$ catalyst were coupled to obtain 2'aminochalcones from nitroacetophenone and benzaldehyde via a one-pot reaction, with yields and selectivities higher than those in typical multistep processes. ${ }^{56}$

\section{Conclusions}

We have shown how supported gold nanoparticles have opened new possibilities for chmoselective hydrogenation of substituted nitroaromatics and this has allowed to discover new reaction processes for producing substituted anilines, imines, oximes, nitrones, azocompounds, and $\beta$ amino carbonyl compounds. Moreover, the research on the reaction mechanism and how gold and the support interact and collaborate during the reaction have taught us how to modify other metal catalysts to expand their scope as catalysts for a number of reactions of fundamental and applied interest.

\section{AUTHOR INFORMATION}

\section{Corresponding Author}

Email: acorma@itq.upv.es

\section{ACKNOWLEDGMENT}

The research was supported by Project CONSOLIDER INGENIO (MULTICAT), PROMETEO, the SEVERO OCHOA

Program for centers of excellence. P.S. thanks the "Subprograma Ramon y Cajal" for the contract RYC-201210662.

\section{REFERENCES}

1 Blaser, H.-U; Steiner, H.; Studer, M. ChemCatChem, 2009, 1, 210-221

2 Dowing, R. S.; Kunkeler, P. J.; van Bekkum, H.. Catal. Today, 1997, 37, 121-136

3 Kabalka, G. W.; Pace, R. D.; Wadgaonkar, P. P. Synth. Commun. 1990, 20, 2453-2458

4 Corma, A.; Serna, P. Science 2006, 313, 332-334

5 Gkizis, P.L.; Stratakis, M.; Lykakis, I.N. Catal. Commun., 2013, 36, 48-51

6 Vasilikogiannaki, E.; Gryparis, C.; Kotzabasaki, V.; Lykakis, I. N.; Stratakis, M. Adv. Synth. Catal. 2013, 355, 907-911

7 Jagadeesh, R. V.; Natte, K; Junge, H;, Beller, M. ACS. Catal. 2015, 15, 1526-1529

8 He, L., Wang; L.-C.; Sun, H.; Ni, J.; Cao, Y.; He, H.-Y.; Fan, K.-N. Angew. Chem. Int. Ed. 2009, 48, 95389541

9 Liu, L.; Qiao, B.; Chen, Z.; Zhanga, J.; Deng, Y.; Chem. Commun. 2009, 653-655

10 Cárdenas-Lizana, F.; Gómez-Quero, S.; Keane, M.A. Catal. Commun., 2008, 9, 475-481

11 Cárdenas-Lizana, F.; Hao, Y.; Crespo-Quesada, M.; Yuranov, I.; Wang, X.; Keane, M.A.; Kiwi-Minsker, L. ACS Catal., 2013, 3, 1386-1396

12 Cárdenas-Lizana, F.; Gómez-Quero, S.; Keane, M.A. Appl. Catal. A Gen., 2008, 334, 199-206

13 Chen, Y.; Qiu, J.; Wang, X.; Xiu, J. J. Catal., 2006, 242, 227-230

14 Corma, A.; Serna, P. Nat Protoc. 2007, 1, 2590 -2595.

15 Boronat, M.; Concepción, P.; Corma, A.; González, S.; Illas, F.; Serna, P. J. Am. Chem. Soc. 2007, 129, 16230 $-16237$

16 Corma, A.; Concepción, P.; Serna, P. Angew. Chem. Int. Ed. 2007, 46, $7266-7269$

17 Corma, A.; Serna, P.; Concepción, P.; Calvino, J.J. J. Am. Chem. Soc. 2008, 130, 8748-8753

18 Corma, A.; Serna, P.; García, H. J. Am. Chem. Soc., 2007, 129, 6358-6359

19 Santos, L.L.; Serna, P.; Corma, A. Chem. Eur. J. 2009, $15,8196-8203$

20 Serna, P.; Concepción, P.; Corma, A. J. Catal. 2009, 265, 19-25

21 Serna, P.; Boronat, M.; Corma, A. Top. Catal. 2011, 54, 439-446

22 Matsushhima, Y.; Nishiyabu, R.; Takanashi, N.; Haruta, M.; Kimura, H.; Kubo, Y. J. Mat. Chem., 2012, 22, 24124-24131

23 Jagadeesh, R.V.; Surkus, A.-E.; Junge, H.; Pohl, M.-M.; Radnik, J.; Rabeah, J.; Huan, H.; Schünemann, V.; Brückner, A.; Beller, M. Science, 2013, 342 1073-1076

24 Mitsudome, T.; Mikami, Y.; Matoba, M.; Mizugaki, T.; Jitsukawa, K; Kaneda, K., Angew. Chem. Int. Ed., 2012, 51, 136-139

25 Furukawa, S.; Yoshida, Y.; Komatsu, T.; ACS Catal., 2014, 4, 1441-1450 
26 Li, G.; Zeng, C; Jin, R. J. Phys. Chem. C, 2015, 119, 11143-11147

27 Makosch, M.; Sá, J.; Kartusch, C.; Richner, G.; van Bokhoven, J.A.; Hungerbühler, K. ChemCatChem 2012, 4, 59-63

28 Combita, D.; Concepción, P.; Corma, J. Catal. 2014, 311, 339-349

29 Blaser, H.-U. Science, 2006, 313, 312-313

30 Haruta M. Catal Today, 1997, 36, 153-166

31 Corma, A.; Boronat, M.; González, S.: Illas, F., Chem. Commun. 2007, 32, 3371-3373

32 Lopez, N.; Janssens, T.V.W.; Clausen, B.S.; Xu, Y.; Mavrikakis, M.; Bligaard, T.; Nørskov, J.K., J. Catal. 2004, 223, 232-235

33 Shimizu, K.-I.; Miyamoto, Y.; Kawasaki, T.; Tanji, T.; Tai, Y.; Satsuma, A. J. Phys. Chem. C, 2009, 113, 17803-17810

34 He, D.; Jiao, X.; Jiang, P.; Wang, J.; Xu, B.-Q. Green Chem., 2012, 14, 111-116

35 Zhang, J.; Chen, G.; Guay, D.; Chaker, M.; Ma, D. Nanoscale, 2014, 6, 2125-2130

36 Cárdenas-Lizana, F.; Gómez-Quero, S.; Hugon, A.; Delannoy, L.; Louis, C.; Keane, M.A.. J. Catal. 2009, 262, 235-243

37 Platinum nanoparticles are embedded on the mesoporous carbon matrix, with terrace sites blocked by carbonaceous species.

38 Makosch, M.; Lin, W.I.; Bumbálek, V.; Sá, J.; Medlin, J.W.; Hungerbühler,K.; Bokhoven. J.A., ACS Catal., 2012, 2, 2079-2081

39 Coq, B.; Tijani, A.; Figueras, F. J. Mol. Catal. A, 1991, 68, 331-345

40 Wei, H.; Liu, X.; Wang, A.; Zhang, L.; Qiao, $\quad$ B.; Yang, X.; Huang, Y.; Miao, S.; Liu. J.; Zhang, T. Nat. Commun., 2014, 5, 5634

41 Tauster, S. J.; Fung, S. C.; Garten, R. J. Am. Chem. Soc. 1978, 100, 170-175

42 Feng, L.; Hoang, D.T.; Tsung, C-K,; Huang, W.; Lo, S. H-Y; Wood, J.B.; Wang, H.; Tang, J.; Yang, P. Nano Res. 2011, 4, 61-71

43 Coq, B.; Tijani, A.; Dutartre, R.; Figueras, F. J. Mol. Catal. A, 1993, 79, 253-264

44 Yarulin, A; Berguerand, C; Alonso, A.O.; Yuranov, I.; Kiwi-Minsker, L. Cat. Today, 256, 241-249

45 Serna, P.; López-Haro, M.; Calvino, J.J., Corma, A. J. Catal. 2009, 263, 328-334

46 GB Patent 860340, 1961, to DuPont

47 Shimizu, K.-I.; Yamamoto, T.; Taic, Y.; Satsuma, A. J. Mol. Catal. A: Chem. 2011 , 345, 54-59

48 Rubio-Marqués, P.; Hernández-Garrido, J.C.; LeyvaPérez, A.; Corma, A. Chem. Commun. 2014, 50, 16451647

49 Oliver-Meseguer, J.; Cabrero-Antonino, J.R.; Domínguez, I.; Leyva-Pérez, A.; Corma, Science, 2012, 338, 1452-1455

50 Robert Bloch, Chem. Rev. 1998, 98, 1407-1438
51 Cisneros, L.; Serna, P.; Corma, A. Angew. Chem., 2014, 126, 9460-9464

52 a) Toshiya, S.; Hamako, H.; (Takasago Perfumery Co LTD), US Patent 5180586, 1993; b) Dennis, D.; Noel, B. (Standard Oil Co.), US Patent 4507212, 1985.

53 Zhang, X.; Corma, A. Angew. Chem. Int. Ed. 2008, 47, $4358-4361$

54 Yamane, Y.; Liu, X.; Hamasaki, A.; Ishida, T.; Haruta, M.; Yokoyama, T.; Tokunaga, M. Org. Lett., 2009, 11, 5162-5165

55 Peng, O.; Zhang, Y.; Shi. F.; Deng, Y.; Chem. Commun. 2011, 47, 6476-6478

56 Climent, M.J.; Corma, A.; Iborra, S.; Marti, L. ACS. Catal. 2015, 5, 157-166 